\title{
Behavior of Steel Plate Girders with Deep Section under Dynamic Effect
}

\author{
Hanady A.El-Rahman El-Dehemy
}

\begin{abstract}
Having a minimum mass, equal-sized flanges and no web stiffeners is the most economical plate girder to fabricate. As with rolled I-sections, for a given section modulus a section with a greater depth will have a lower mass than one with a smaller depth, except in some instances where a thicker web is required in the deeper section. A wider flange plate to resist the buckling tendency may be necessary to use, when the compression flange is laterally unrestrained, but this will add to the cost because of the more difficult assembly procedure. In order to arrive at a minimum-mass cross section as much as possible of the material should be located in the flanges and as little as possible in the web, consistent with shear requirements. There is usually an advantage, however, in using a somewhat thicker web in order to reduce welding distortion, or to avoid the use of or number of stiffeners. It can be shown that for a given web depth to thickness ratio the minimum-mass cross section is that in which the area of the two flanges combined equals that of the web, i.e. $2 A f=A w . A n$ important consideration in cost reduction is the use of preferred plate widths and thicknesses for the flange and web elements.
\end{abstract}

Keywords: Steel Girders, Finite Element, ABAQUS software.

\section{INTRODUCTION}

To carry heavy loads on relatively long spans, a flexural member is required as a girder. Girders are flexural members that support beams which frame into them are sometimes, in building construction regardless of the magnitude of the loads. Depending on the magnitude of the loads and the span length, these girders may be factory manufactured rolled cross sections or built-up sections. A flexural cross section made up of a number of elements can be describing by the term girder. They are generally considerably deeper than the deepest rolled sections and usually have webs which are relatively thinner than rolled sections. See "Fig. 1". The difference between beams, built-up sections and plate girders as follow:

The beams are normally used for shorter spans and usually consist of ready made available rolled section. For the built-up sections are used for sections for which ready made available beam sections are not sufficient. The additional requirement of moments are compensated by using additional plates connected to the flanges of available I, or channel sections and they are called as built up beams.

Revised Manuscript Received on September 25, 2020.

* Correspondence Author

Hanady El-Dehemy*, lecturer at Civil Engineering Department, Higher Institute of Engineering and Technology, Kafr-elsheikh, Egypt. Email: hanadyeldehemy@gmail.com

(c) The Authors. Published by Blue Eyes Intelligence Engineering and Sciences Publication (BEIESP). This is an open access article under the CC BY-NC-ND license (http://creativecommons.org/licenses/by-nc-nd/4.0/)
The plate girders are used to carry extensively large loads such as bridges. Web plates or flanges plates are connected as an assembly by means of suitable angles. Moreover since the plate girder is expected to carry huge loads, horizontal and vertical stiffeners are also used to avoid excess buckling and also at places where concentrated loads are acting. A flange plates may be added over the flange angles, to increase the moment of resistance. The plates may be curtailed where the bending moment to be resisted decreases and plates are not required. The depth over angles is taken as $1 / 10$ to $1 / 12$ of span. Especially cases for heavy concentrated loads are made deeper up to $1 / 8$ of span. The distance between centers of gravity of the top flange and bottom flange is defined as effective depth, which is approximately taken as depth over angles.

\section{REVIEW CRITERIA}

Limiting width-to-thickness ratios were studies to made I-girders composed of high strength steel by Earls [1]. He was observed that a decoupling of local and lateral-torsional buckling phenomena is not possible. A model to account for the interaction between local (including flange and web) and lateral-torsional buckling was proposed by Kemp [2]. The test results were analyzed by Kemp [3] and found out the existence of a much better relationship between rotation capacity and generalized slenderness, if the latter included the slenderness of both local buckling and lateral-torsional buckling. Shokouhian M. [4] proposes a classification of flexural members based on rotation capacity at the member level for the latest version of the Chinese steel design code which takes into account interaction between local and local overall buckling modes. But the members studied in this research were only composed to pure bending, and support from testing results were lacking. An experimental study of H-section steel beam- columns with large width-to-thickness ratios subjected to combined forces was presented by Cheng Xin [5-6]. Conclusion that the one of the significant features that influences cross-sectional behavior is web - flange interaction is but has received little consideration. The necessity for current specifications to improve those rules has been highlighted. However, there are few corresponding numerical studies in existing literatures, and more experimental investigations for I-girders with high shear ratio were in need.

Published By:

Blue Eyes Intelligence Engineering and Sciences Publication 


\section{Behavior of Steel Plate Girders with Deep Section under Dynamic Effect}

Strength calculation is another key point in design process. The steel plate girders were studied are commonly used to support vertical loads from large facilities. They are usually composed of compact flanges, non-compact or slender webs.

In these cases web panels are subjected to combination of shear and bending, while the shear force is greater than half the plastic shear resistance. Shear is carried only by the web was assumed by Basler [7], the maximum shear resistance is reached when the tension field in the web is fully utilized. Further design models were based on Basler's assumption with different modifications on shear resistance of the web plate and the interaction model. For each of the methods the ultimate shear resistance is defined with modified collapse mechanism. The method is based on the calculation of the effective cross-section characteristics, and the shear resistance is derived from a tension field model in the web.
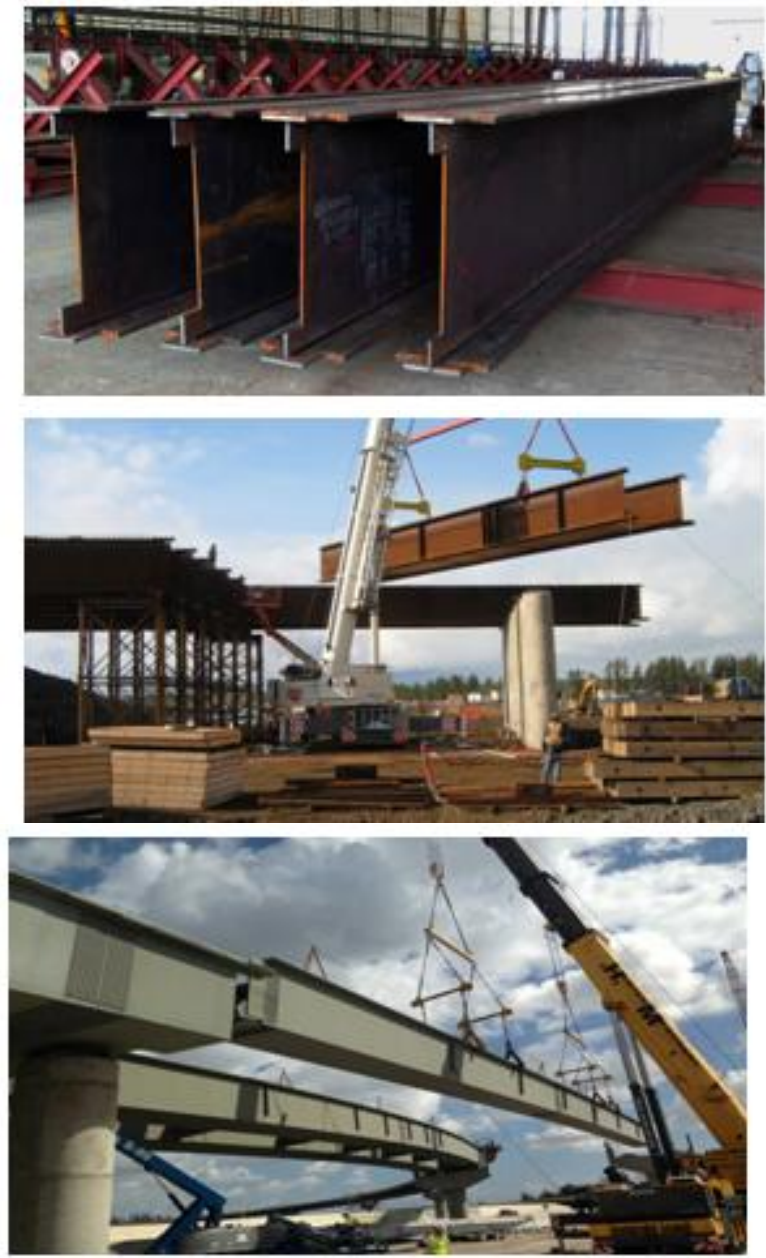

Fig. 1.Example of a Steel Plate Girders.

\section{FINITE ELEMENT ANALYSIS}

ABAQUS software provides a good analysis for design various structural systems. ABAQUS model easily modeled steel plate girders. A present study focus on the analysis of deflection and stresses for steel plate girder by dynamic nonlinear analysis.

\section{A. Finite Element Modeling}

A finite element model of steel deep beam type I beam with dimension 600x180x8x16, with $3.0 \mathrm{~m}$ span length and 120 $\mathrm{N} / \mathrm{m} 2$ uniform loads. The parametric studies on this model will be as different ends conditions (hinged or fixed ends. The comparison between results in deflection and stresses.

\section{B. Figures}

Fig.2 shows the nonlinear dynamic vertical displacement for fixed analysis with maximum values $=-1.639 \mathrm{E}-2 \mathrm{~mm}$. Fig.3, shows the nonlinear dynamic vertical displacement for hinged analysis with maximum values $=-5.295 \mathrm{E}-2 \mathrm{~mm}$. Fig.4, shows the nonlinear dynamic stress in plane for fixed analysis. Fig. 5 shows the nonlinear dynamic stress in plane for hinged analysis.

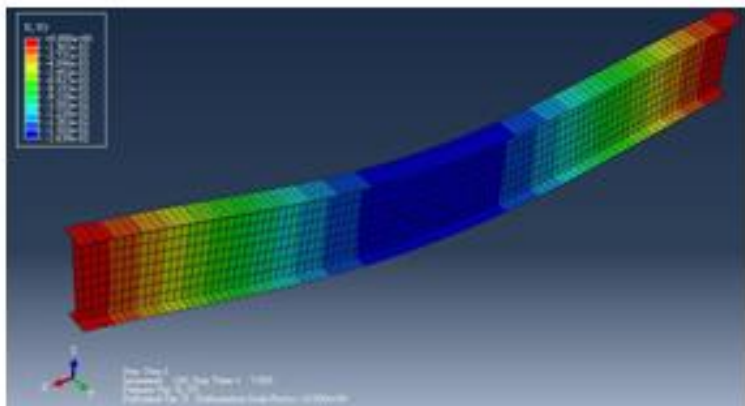

Fig. 2.Nonlinear Vertical Dynamic Displacement for Fixed Analysis.

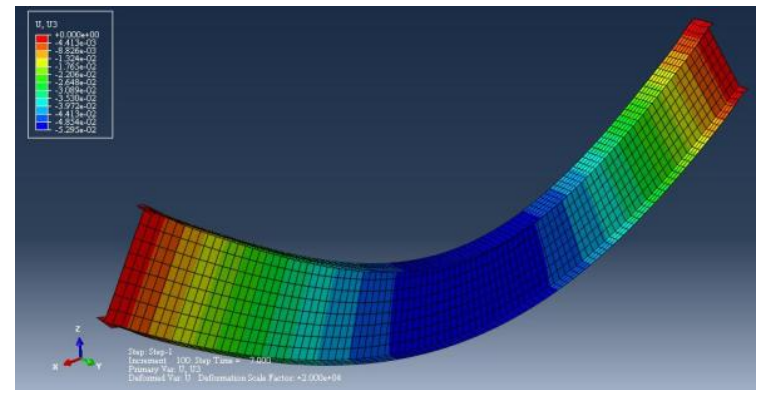

Fig. 3.Nonlinear Vertical Dynamic Displacement for Hinged Analysis.

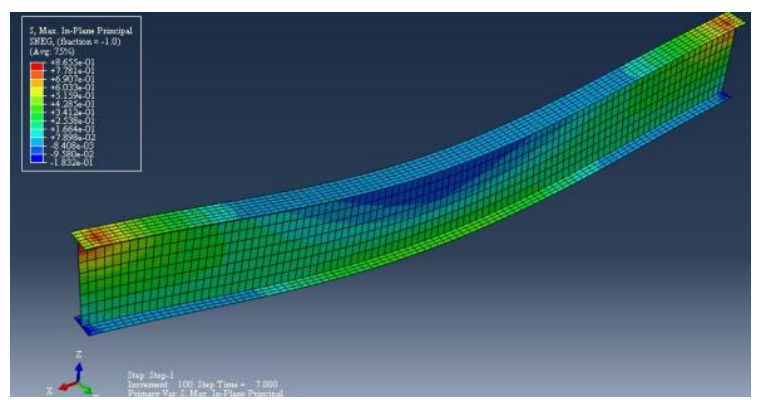

Fig. 4.NonlinearDynamic Max. In Plane Stress for Fixed Analysis

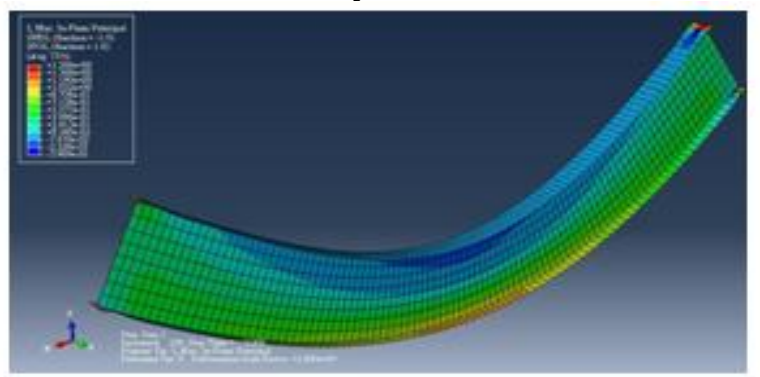

Fig. 5.Nonlinear Dynamic Max. In Plane Stress for Hinged Analysis.

Published By:

Blue Eyes Intelligence Engineering and Sciences Publication (C) Convriaht: All riahts reserved.

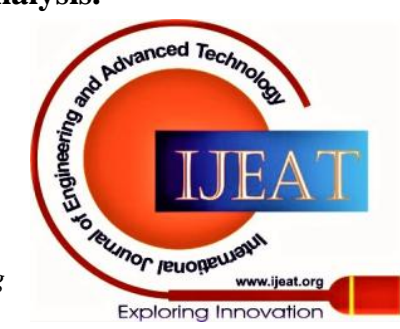




\section{RESULT AND DISCUSSION}

This research presented here an ABAQUS finite element models software to achieve the structural response of steel plate girders with deep section under dynamic effect in terms of stress distributions, and deflection.

The analysis carried out using geometric and material non-linearities. The accomplishment also concluded hinged and fixed end conditions analysis. The results obtained from above analysis are:

1) The nonlinear dynamic vertical displacement for fixed analysis with maximum values $=-1.639 \mathrm{E}-2 \mathrm{~mm}$. Where for hinged analysis, the maximum values of nonlinear dynamic vertical displacement $=-5.295 \mathrm{E}-2 \mathrm{~mm}$.

2) The nonlinear dynamic stress in plane for fixed analysis with maximum values $=-1.832 \mathrm{E}-1 \mathrm{~N} / \mathrm{mm}^{2}$. Where for hinged analysis, the maximum values of stresses = $-3.909 \mathrm{E}-1 \mathrm{~N} / \mathrm{mm}^{2}$.

\section{CONCLUSION}

A conclusion from the previous sectors is the analysis of nonlinear for steel plate deep section under dynamic effect for hinged end conditions (for vertical displacements and also for stresses) gives a higher values than the analysis for fixed end conditions for the same type of beams. Experimental tests for steel plate girders with deep sections under different cases of dynamic effects are required.

\section{REFERENCES}

1. Earls, C. J, "On the inelastic failure of high strength steel i-shaped beams". Journal of Constructional Steel Research, 1999, 49(98), 1-24.

2. Kemp AR, "Factors affecting the rotation capacity of plastically designed members". Journal of Structural Engineering, 1986, 64B (2): 2835.

3. Kemp, A. R., "Inelastic local and lateral buckling in design codes". Journal of Structural Engineering, 2014, 122(4), 374-382.

4. Shokouhian, M., \& Shi, Y, "Classification of i-section flexural members based on member ductility". Journal of Constructional Steel Research.2014,95(3), 198-210.

5. Cheng, X., Chen, Y., \& Nethercot, D. A. "Experimental study on $\mathrm{H}$-shaped steel beam-columns with large width-thickness ratios under cyclic bending about weak-axis". Engineering Structures, 2013, 49, 264-274.

6. Cheng, X., Chen, Y., \& Pan, L., "Experimental study on steel beam-columns composed of slender H-sections under cyclic bending". Journal of Constructional Steel Research". 2013, 88, 279-288.

7. Basler $\mathrm{K}$. "Strength of plate girders under combined bending and shear". 1961, Journal Structure Div ASCE, 87.

\section{AUTHORS PROFILE}

Dr. Hanady A.ElRahman ElDehemy working as lecturer of steel structures at lecturer at Civil Engineering Department, Higher Institute of Engineering and Technology, Kafr-elsheikh, Egypt, preparing for Associate professor.

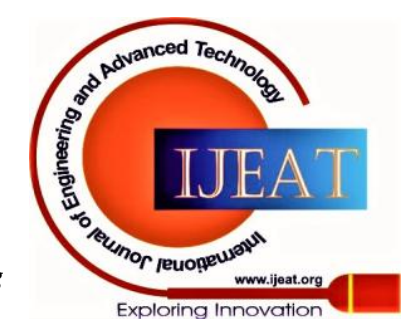

